established the place of his department in the medical school and developed his unit at the Southern General Hospital where he exerted a strong influence on the development of general hospital based psychiatry.

His earlier training in Meyerian principles of psychobiology led him to develop an eclectic approach to patient care. He formed close links with other medical specialists and was quick to see the contribution which could be made by all types of professional staff. His students and juniors were well trained in both psychotherapeutic and physical approaches to treatment. He was co-author of a successful textbook on Psychology in Relation to Medicine.

Although a hy man he had a wide circle of friends from many walks of life, and his range of interest in Scottish politics, literature and the arts made him a much admired companion, counsellor and host. He was particularly at ease with young people, whose enthusiasms he shared and respected.

During his tenure of the Chair he held many appointments nationally and internationally. He travelled widely for WHO as a member of the
Expert Committee on Mental Health. He became honorary consulting psychiatrist to the Army in Scotland and his opinion on the place of psychiatry in the armed forces was sought regularly. He played a major part in the growth and development of the Royal Medico-Psychological Association both in Scotland, where he was Chairman of the Scottish Division in 1962 and nationally, becoming President in 1965. Thereafter he was closely concerned in the creation of the Royal College of Psychiatrists and helped to shape its educational policies. He was dedicated to involving younger psychiatrists in its affairs. When the College received its Royal Charter in 197 t he was made an Honorary Fellow.

His later years were marred by poor health which he bore with uncomplaining courage. A serious illness in 1972 caused him to retire at the beginning of his last year in office, and his continuing ill health in the following years was a source of deep distress to his family and his many friends. He is survived by his wife, two sons and a daughter who is a consultant physician.

Geral.d Timbuky

\title{
COLLEGE ANNOUNCEMENTS
}

\section{Autumn Quarterly Meeting}

The Autumn Quarterly Meeting will be held in London on 16 and 17 November 1978. The programme will probably include papers on Depression, Violence, Adolescence, and Marital Problems. The

\section{College Shopping}

A College Chriatmas Card will be available for sale shortly. Members may also be interested in purchasing a plaque bearing the College Arms in full colour, which will also be available in the near future. Details will be published in the next issue of the Bulletin, but those desiring further information before then are invited to telephone the College (o1-235 2351).

Maudsley Lecture will be given by Professor Seymour S. Kety of the McLean Hospital, Massachusetts. Full details will be sent to members shortly.

Members are reminded that the College now has its own necktie. This is dark blue with the College Arms in yellow and white, and is manufactured to a high standard in polyester Crimplene. It is available to members at $£ 3.00$, plus 12p for postage and packing (inland), 5op (Air Mail overseas). Orders should be sent to the Royal College of Psychiatrists, with a cheque for the appropriate amount.

\section{JOINT MEETING WITH THE GLINICAL GENETICS SOCIETY}

This meeting will be held on Wednesday, 15th November, at the Royal Society of Medicine, I Wimpole Street, London $\mathrm{W}_{\mathrm{I}}$, from $10 \mathrm{am}-4 \mathrm{pm}$. The programme will include sessions on the following topics:

Schizophrenia (opening speaker, Dr Derek Richter);

Sex chromosome abnormalities (opening speaker, Dr Valerie Cowie);

Huntington's chorea (opening speaker, Dr Adrian Caro).
A dinner for members of the College and of the Society will be held on the evening of the previous day, Tuesday 14 November, also at the RSM.

Full details will be sent to members of the College with the programme for the Autumn Quarterly Meeting (see above) or may be obtained from Professor K. M. Laurence, Honorary Secretary, Clinical Genetics Society, Department of Child Health, Welsh National School of Medicine, Heath Park, Cardiff $\mathrm{CF}_{4}$ 4XN. 